\title{
Diabetes and Female Sexual Dysfunction
}

\author{
Lovely Gupta, ${ }^{1}$ Swarnima Prakash, ${ }^{2}$ Deepak Khandelwal, ${ }^{3}$ Bharti Kalra, ${ }^{4}$ and Sanjay Kalra ${ }^{5}$ \\ 1. Department of Food \& Nutrition, Lady Irwin College, Delhi University, New Delhi, India; 2. Department of Dietetics, Maharaja Agrasen Hospital, \\ Punjabi Bagh, New Delhi, India; 3. Department of Endocrinology \& Diabetes, Maharaja Agrasen Hospital, Punjabi Bagh, New Delhi, India; \\ 4. Department of Gynecology, Bharti Hospital, Karnal, Haryana, India; 5. Department of Endocrinology, Bharti Hospital, Karnal, Haryana, India
}

A normal sex life is an important part of life and relationships. Diabetes mellitus (DM) is an important cause of sexual dysfunction both in men and women. This problem is more difficult to diagnose and treat in women than in men because of the intricacy of the female sexual response. Also, the literature is limited addressing female sexual dysfunction (FSD) in DM, and this aspect of female health, is often ignored in clinical practice in women with DM. Early screening, diagnosis, and appropriate counseling are the cornerstone for managing FSD in women with DM. The current review aims to update the scenario of prevailing sexual dysfunction faced by the women with diabetes, their etiology, diagnostic approaches, and its management.

\section{Keywords}

Sexual dysfunction, female, diabetes, hyperglycemia, sexual distress, female arousal disorder, dyspareunia, vulvodynia

Disclosures: Lovely Gupta, Swarnima Prakash, Deepak Khandelwal, Bharti Kalra, and Sanjay Kalra have nothing to disclose in relation to this article. No funding was received for the publication of this article.

Review Process: Double-blind peer review.

Authorship: All named authors meet the International Committee of Medical Journal Editors (ICMJE) criteria for authorship of this manuscript, take responsibility for the integrity of the work as a whole, and have given final approval to the version to be published.

Compliance with Ethics: This study involves a review of the literature and did not involve any studies with human or animal subjects performed by any of the authors.

open Access: This article is published under the Creative Commons Attribution Noncommercial License, which permits any non-commercial use, distribution, adaptation and reproduction provided the original author(s) and source are given appropriate credit. (C) The Authors 2018

Received: February 26, 2018

Accepted: April 12, 2018

Citation: US Endocrinology, 2018;14(1):35-38

Corresponding Author: Deepak Khandelwal, Department of Endocrinology \& Diabetes, Maharaja Agrasen Hospital, Punjabi Bagh, New Delhi, India. E: khandelwalaiims@gmail.com

Support: No funding was received in the publication of this article.

\section{Introduction}

Diabetes mellitus (DM) is a group of metabolic disorders characterized by high blood glucose levels. According to International Diabetes Federation (IDF) 2017 data, there were 425 million persons with DM worldwide, and that is expected to reach 629 million by $2045 .{ }^{1}$

Normal sexual health is a dynamic and harmonious state involving erotic and reproductive experiences, and fulfillment within a broken physical, emotional, interpersonal, social, and spiritual sense of wellbeing, in a culturally informed, freely and responsibly chosen and ethical framework; not merely the absence of sexual disorders. ${ }^{2}$ Female sexual dysfunction (FSD) is a complex set of conditions associated with multiple biological, medical, psychological, and social risk factors. ${ }^{3,4}$ The World Health Organization (WHO) defines FSD as "the various ways in which a woman is unable to participate in a sexual relationship as she would wish." ${ }^{5}$ Desire, arousal and orgasm are three principle stages of sexual response cycle. ${ }^{6}$ FSD is characterized by lack or loss of desire, sexual aversion, lack of sexual enjoyment, vaginal dryness, markedly delayed or nonexistent orgasm, vaginismus, and dyspareunia. A clinically useful definition of FSD is "the persistent/recurring decrease in sexual desire or arousal, the difficulty/inability to achieve an orgasm, and/or the feeling of pain during sexual intercourse." ${ }^{\prime \prime, 6}$

DM is an important cause of sexual dysfunction (SD) both in men and women. ${ }^{7}$ SD is more difficult to diagnose and treat in women than it is in men because of the intricacy of the female sexual response. ${ }^{8,9}$ Although SD in males with DM is widely explored, there is limited literature regarding FSD and DM and it is often a neglected health issue in women with diabetes. ${ }^{7}$ However, it affects the overall quality of life, physical and emotional health, and deserves more attention in clinical practice as well as in clinical research. ${ }^{10}$ The aim of this review is to update the scenario of prevailing SD faced by the women with DM, their etiology, diagnostic approaches, and its management.

\section{Prevalence of female sexual dysfunction}

SD is common in people with DM. ${ }^{11}$ The global prevalence of SD in women with DM is estimated to be 20-80\% ${ }^{12,13}$ A systematic review published in 2016 by McCool et al. estimated the global prevalence of FSD among premenopausal women to be $40.9 \%$ (95\% Cl 37.1-44.7, $12=99.0 \%) .{ }^{14} \mathrm{SD}$ also increases in transition from early to late menopause. ${ }^{15}$ Systematic reviews and meta-analyses have reported a higher frequency of FSD in women with DM. ${ }^{16,17}$ A meta-analysis by Pontiroli et al showed a higher frequency of SD among women with type $1 \mathrm{DM}$ (T1DM; OR [95\% Cl] 2.27 [1.23, 4.16]), T2DM (OR [95\% Cl] $2.49[1.55,3.99])$, and in any diabetes (T1 and T2; OR [95\% $\mathrm{Cl}] 2.02[1.49,2.72])$ than in control women.16 
Table 1: Pathophysiological mechanisms causing sexual dysfunction in women with diabetes ${ }^{22-30}$

\begin{tabular}{|c|c|}
\hline Causes & Mechanisms \\
\hline Hyperglycemia & $\begin{array}{l}\text { - Reduces hydration of mucus membranes, including vaginal mucosa } \\
\text { - Result in poor vaginal lubrication, dyspareunia and genitourinary infections }\end{array}$ \\
\hline Vaginal/urinary tract infections & $\begin{array}{l}\text { - Sexual discomfort by causing itching, burning, irritation, urgency, vaginal dryness or discharge } \\
\text { - Pain/general discomfort in the pelvic region }\end{array}$ \\
\hline Vascular complications & - Can affect blood supply to vagina and clitoris which can cause problems with dryness and arousal \\
\hline Neuropathy and neurological disorders & $\begin{array}{l}\text { - Structural and functional changes in female genitalia } \\
\text { - } \text { Reduced sensitivity and impaired sexual response } \\
\text { - Stroke, epilepsy, and traumatic brain injury can also cause significant impairment in sexual functioning }\end{array}$ \\
\hline Hormonal & $\begin{array}{l}\text { - Low estrogen levels can affect lubrication of vagina } \\
\text { - Estrogen deficiency also manifest as a poor general condition, lethargy, loss of interest, fatigue, and depression } \\
\text { - Androgen deficiency also plays an important role in the pathophysiology of low libido in women }\end{array}$ \\
\hline Psychological & $\begin{array}{l}\text { - Anxiety, stress, low self-esteem issues, body image perception disorders, fear of rejection, sexual performance anxiety, } \\
\text { traumatic sexual experience in the past, and history of abuse }\end{array}$ \\
\hline Depression & $\begin{array}{l}\text { - Diabetes and depression have bidirectional relationship } \\
\text { - Depression may impair lifestyle (alcohol abuse/smoking), self-image and relationship status, thus indirectly affecting sexual } \\
\text { desire and arousal }\end{array}$ \\
\hline Sociocultural & $\begin{array}{l}\text { - Limited social relations, financial difficulties, employment status, religious beliefs, educational background, and lack of } \\
\text { exercise }\end{array}$ \\
\hline
\end{tabular}

However, data from conservative societies like Middle Eastern and South Asian countries is limited. A cross-sectional study conducted in Iran (2012-2013) reported that 53.6\% women (age 30-55 years) with T2DM had FSD. ${ }^{18}$ In a North Indian study $45.19 \%$ women suffered from desire disorder, $62.71 \%$ from arousal disorder, $84.75 \%$ from orgasmic disorder, and $20.38 \%$ from pain disorder. Also, significant number of women had lower self-esteem, felt less attractive, accepted their detrimental sexuality and believed in their reduced "desirability" in their spouse's eyes'. Only $3.95 \%$ of women had previously discussed these issues with a healthcare provider, while $83.59 \%$ would prefer this type of counseling with their diabetes care team. ${ }^{19}$. A study conducted in South India has shown that sexual problems seems to be more prevalent among less educated women with age above 40 years ${ }^{20}$

\section{Etiology}

FSD is multifactorial disorder involving subjective and objective aspects of sexual function, with numerous contributing factors (hormonal, psychological, interpersonal, and social). DM is known to cause different medical, psychological, and sexual complications. Evidence shows significant association between female sexual health and vascular risk factors (hypertension, hyperlipidemia, metabolic syndrome/obesity, diabetes, and coronary heart disease).21,22 Women with DM may have less sexual desire which can be due to depression or changes in blood glucose levels that can leave them feeling tired or irritable..1,23 FSD can also be an early symptom that leads to the diagnosis of DM. ${ }^{11}$ The pathophysiological mechanisms that play an important role in the causation of FSD among persons with DM, have been summarized in Table 1.22-30

FSD in persons with DM has repeatedly shown to be correlated with psychological distress. ${ }^{31}$ Significant ethnic and gender differences are known to exist in acceptance of disease, receiving social support, disease knowledge and perceived difficulty in self-management behaviors, glycemic control, and quality of life among T2DM patients. This negative appraisal is independent of duration of diabetes. ${ }^{26}$ Improved education and support for women with DM may result in better disease management, a more positive outlook regarding their health, and thus an improvement in sex life.

Additionally, FSD is correlated with lower education, lower income, urinary tract symptoms, cancer survivors, history of sexual abuse, trauma to genitalia, use of antidepressants, and disturbed spousal support. ${ }^{6}$ Many women in conservative societies such as South Asia experience inaccessibility of trained female healthcare professionals, lack of privacy and confidence, and a social taboo attached to the subject of sexual health. ${ }^{31}$ This is compounded by health and gender inequity and a lack of resources or medical services.

\section{Symptoms and signs of female sexual dysfunction ${ }^{29,32,33}$}

- Hypoactive sexual desire: decrease or loss of desire for sex

- Inadequate vaginal lubrication before and during intercourse

- Inability to achieve orgasm

- Inability to relax the vaginal muscle enough to allow intercourse (vaginismus)

- Pain during intercourse: vulvodynia

- Non-coital sexual pain disorder (recurrent or persistent genital pain induced by non-coital sexual stimulation)

\section{Screening and diagnostic methods}

To identify whether a diabetic woman has sexual dysfunction, a detailed history and examination is the first step. This can be done by their primary care physicians or anyone from their diabetes care team. ${ }^{32}$ The consultation should focus on the woman's current interpersonal and psychosocial status, her sexual and medical history, comorbid illnesses, enquiries about sexual abuse or other traumatic sexual experiences, number of sexual partners, impact of religious and social beliefs on sexuality, as well as her current diabetes treatment. ${ }^{4}$ History should be inclusive of menstrual abnormalities and infertility. Diabetes has been associated with menstrual abnormalities, such as oligomenorrhea, secondary amenorrhea, delayed menarche, and 
premature menopause which diminishes the patient's reproductive period. Evidence shows that better glycemic control improves such irregularities and increases fertility rates. ${ }^{34}$ History and examination needs to be done in comfortable environment with use of flexible conversations and also structured interviews. Several self-reported validated questionnaires such as Female Sexual Function Index (FSFl; most frequently used in research), the Brief Index of Sexual Functioning for Women (BISF-W), the Derogatis Interview for Sexual Function (DISF/DISFSR), and the Female Sexual Distress Scale (FSDS) have been developed to assess FSD in clinical practice as well as for research purpose. The principal components of the most commonly used scale, FSFI, include desire, subjective arousal, lubrication, orgasm, satisfaction, and pain. ${ }^{32,35}$ Similarly two models have been proposed namely ALLOW (Ask, Legitimize, Limitations, Open up, Work together) and PLISSIT (Permission, Limited Information, Specific Suggestions, Intensive Therapy) consisting of simple domains to facilitate further evaluation by probing about sexual life, discussions, limitations, specific suggestions and intensive treatment. ${ }^{36}$

Selected women may need laboratory work up for hypothalamic-pituitaryovarian axis and the hormonal status including hyperandrogenism. Several possible determinants of FSD including autonomic neuropathy, vaginitis, pelvic inflammatory diseases, urinary tract infection, and female genital mutilation, can be diagnosed by good history, examination, and selective work up. ${ }^{37}$

\section{Treatment}

Treatment of FSD depends on underlying etiology and is a multi-disciplinary task. Treatment options are summarized in Table 2.21,38,39 Intensive lifestyle interventions in terms of diet and exercise have shown beneficial effects on sexual functioning especially among obese women with diabetes..$^{40} \mathrm{~A}$ healthy diet, routine exercise, avoiding smoking, and usage of appropriate therapies for optimum glycemic and metabolic control (including control of hypertension and dyslipidemia) are the key to preventing and managing progression of diabetes-induced sexual problems. ${ }^{23}$ Omega-3 fatty acids may be beneficial in general well-being, improvement in libido, and prevention of menstrual syndromes, such as dysmenorrhea and postmenopausal hot flushes by reducing the production of eicosanoid proinflammatory molecules. ${ }^{41,42}$ Many cases of FSD can be treated with simple interventions like treatment of and underlying genital infection. Vaginal lubricants and moisturizers are helpful for vaginal dryness in women with DM who are postmenopausal, or those with hyperglycemia who complain of vaginal dryness or dyspareunia.

Limited evidence has shown that dehydroepiandrosterone (DHEA) may improve libido and well-being among postmenopausal women. It provides a large precursor reservoir for the intracellular production of androgens and estrogens in non-reproductive tissues, restoring the circulating levels of these steroids to improve well-being and sexual function. ${ }^{43}$ Flibanserin, a
Table 2: Treatment options for sexual problems in women with diabetes ${ }^{21,38,39}$

\begin{tabular}{|c|c|}
\hline Sexual problem & Treatment \\
\hline $\begin{array}{l}\text { Reduced vaginal } \\
\text { lubrication }\end{array}$ & $\begin{array}{l}\text { - Education regarding need for adequate stimulation } \\
\text { - } \text { - Water-based to penetration } \\
\text { - Hormone replacement lubricants } \\
\text { - Arousal enhancement strategies }\end{array}$ \\
\hline Genital infections & $\begin{array}{l}\text { - Treatment of genital infections } \\
\text { - Genital hygiene education }\end{array}$ \\
\hline Vulvodynia/dyspareunia & $\begin{array}{l}\text { - Investigation and treatment of underlying condition } \\
\text { - Lubricants } \\
\text { - Reduced focus on penetrative sex }\end{array}$ \\
\hline $\begin{array}{l}\text { Anorgasmia (inability to } \\
\text { orgasm) }\end{array}$ & $\begin{array}{l}\text { - Penetrative/non-penetrating vibrating sex aids } \\
\text { - Clitoral therapy devices } \\
\text { - Psychosexual support }\end{array}$ \\
\hline Reduced libido & $\begin{array}{l}\text { - Review and treat any concurrent depressive illness } \\
\text { - Psychosexual support for any self- image issues } \\
\text { - DHEA supplementation } \\
\text { - Estrogen/androgen replacement } \\
\text { - Flibanserin (serotonin } 1 \mathrm{~A} \text { receptor agonist and a } \\
\text { - serotonin } 2 \mathrm{~A} \text { receptor antagonist) } \\
\text { - PDE-5 inhibitors }\end{array}$ \\
\hline
\end{tabular}

$D H E A=$ dehydroepiandrosterone; $P D E-5=$ phosphodiesterase type -5 .

serotonin $1 \mathrm{~A}$ receptor agonist and a serotonin $2 \mathrm{~A}$ receptor antagonist, is the only US Food and Drug Administration (FDA)-approved agent for generalized acquired hypoactive sexual desire in premenopausal women. However, patients need to be counseled for increased risk of severe hypotension and syncope. Also, data in women specifically with DM is limited. ${ }^{44,45}$

Certain medications may enhance the vasocongestive response for women with genital arousal disorder. Systemic as well as transdermal estrogen replacement and androgen replacement are being used to increase sex hormone binding globulin, reduce bioavailable testosterone, improve genital response, and improve the mental response. ${ }^{4-46}$ Further, phosphodiesterase inhibitors are upcoming treatments to improve sexual function but require future investigations for safety and effective concerns. ${ }^{47,48}$

\section{Future directions}

Further studies are needed to better understand occurrence of SD and its impact on quality of life among women with DM, especially from conservative societies. Future studies may identify appropriate medical professionals to probe and explore the related issues for early screening. More studies are needed before the role of newer treatments, such as DHEA supplementation, estrogen/androgen replacement, and flibanserin can be established. $\square$
1. International Diabetes Federation. IDF Diabetes Atlas, 8th edn Brussels, Belgium:International Diabetes Federation, 2017. Available at: http://www.diabetesatlas.org/resources/2017-atlas. html (accessed April 10, 2018)

2. Rochester-Eyeguokan C, Meade L. A Practical approach to managing hypoactive sexual desire disorder in women with diabetes. Diabetes Ther. 2017:8:991-8.

3. Allahdadi KJ, Tostes RC, Webb RC. Female sexual dysfunction: therapeutic options and experimental challenges. Cardiovasc Hematol Agents Med Chem. 2009;7:260-9.

4. $\mathrm{NIH}$ Consensus Conference. Impotence. $\mathrm{NIH}$ Consensus Development Panel on Impotence. JAMA. 1993;270:83-90.

5. WHO, Defining sexual health. Available at: www.who.int/ reproductivehealth/topics/sexual_health/sh_definitions/en/ (accessed April 5, 2018)

6. Sharma JB, Kalra B. Female sexual dysfunction: assessment. J Pak Med Assoc. 2016;66:623-6.

7. Omidvar S, Niaki MT, Amiri FN, Kheyrkhah F. Sexual dysfunction among women with diabetes mellitus in a diabetic center in Amol. J Nat Sci Biol Med. 2013:4:321-4.

8. Elder JA, Braver Y. Female sexual dysfunction. In: Current clinical medicine. Elsevier; 2010:1222-6.

9. Enzlin P, Mathieu C, Van Den Bruel A, et al. Prevalence and predictors of sexual dysfunction in patients with type 1 diabetes. Diabetes Care. 2003;26:409-14.

10. Laumann EO, Paik A, Rosen RC. Sexual dysfunction in the United
States: prevalence and predictors. JAMA. 1999;281:537-44. 11. Edwards D. Sexual health and dysfunction in men and women with diabetes. Diabetes \& Primary Care. 2013;15:309-18.

12. Elyasi F, Kashi Z, Tasfieh B, et al. Sexual dysfunction in women with type 2 diabetes mellitus. Iran J Med Sci. 2015;40:206-13.

13. Doruk H, Akbay E, Cayan $\mathrm{S}$, et al. Effect of diabetes mellitus on female sexual function and risk factors. Arch Androl. 2005:51:1-6.

14. MCCool ME, Zuelke A, Theurich MA, et al. Prevalence of female sexual dysfunction among premenopausal women: a systematic review and meta-analysis of observational studies. Sex Med Rev. 2016:4:197-212.

15. Dennerstein L, Randolph J, Taffe J, et al. Hormones, mood, 
Review Diabetes

sexuality, and the menopausal transition. Fertil Steril. 77:Supp 4:42-8.

16. Pontiroli AE, Cortelazzi D, Morabito A. Female sexual dysfunction and diabetes: a systematic review and meta-analysis. J Sex Med. 2013; 10:1044-51.

17. Enzlin $P$, Rosen R, Wiegel $M$, et al. Sexual dysfunction in women with type 1 diabetes. Diabetes Care. 2009:32:780-5.

18. Vafaeimanesh J, Raei M, Hosseinzadeh F, Parham M. Evaluation of sexual dysfunction in women with type 2 diabetes. Indian 」 Endocrinol Metab. 2014;18:175-9.

19. Kalra B, Kalra S, Chawla K, et al. Sexual attitudes, knowledge and function of women with diabetes. The Internet Journal of Geriatrics and Gerontology. 2009:5.

20. Singh JC, Tharyan P, Kekre NS, et al. Prevalence and risk factors for female sexual dysfunction in women attending a medical clinic in south India. J Postgrad Med. 2009:55:113-20.

21. Miner M, Esposito K, Guay A, et al. Cardiometabolic risk and female sexual health: the Princeton III summary. J Sex Med 2012;9:641-51.

22. Shivananda MJ, Rao TS. Sexual dysfunction in medical practice. Curr Opin Psychiatry. 2016;29:331-5.

23. Maiorino ML, Bellastella G, Esposito K. Diabetes and sexual dysfunction: current perspectives. Diabetes Metab Syndr Obes. 2014;7:95-105.

24. Devido JA, Sereika SM, Cohen SM, Charron-Prochownik D. Race and religious beliefs are associated with communication regarding reproductive health and preconception counseling in young women with diabetes. Diabetes Educ. 2016;42:721-7.

25. Esposito K, Maiorino MI, Bellastella G, et al. Determinants of female sexual dysfunction in type 2 diabetes. Int I Impot Res.
2010;22:179-84.

26. Fatemi SS, Taghavi SM. Evaluation of sexual function in women with type 2 diabetes mellitus. Diab Vasc Dis Res. 2009;6:38-9.

27. Gandhi J, Dagur G, Warren K, et al. The role of diabetes mellitus in sexual and reproductive health: an overview of pathogenesis, evaluation, and management. Curr Diabetes Rev. 2017;13:573-81.

28. Lue TF, Brant WO, Shindel A, Bella AJ. Sexual Dysfunction in Diabetes. In: De Groot LJ, Chrousos G, Dungan K, et al, Endotext, South Dartmouth, MA, US: MDText.com, Inc., 2000-2017.

29. Gandhi J, Dagur G, Warren K, et al. Effect of diabetes mellitus on sexual arousal and intercourse. Trans/ Biomed. 2016;7:2.

30. Grandjean C, Moran B. The impact of diabetes mellitus on female sexual well-being. Nurs Clin North Am. 2007;42:581-92.

31. Bajaj S, Jawad F, Islam N, et al. South Asian women with diabetes: Psychosocial challenges and management: Consensus statement. Indian J Endocrinol Metab. 2013;17:548-62.

32. Kizilay F, Gali HE, Serefoglu EC. Diabetes and sexuality. Sex Med Rev. 2017;5:45-51.

33. Kalra B, Kalra S, Bajaj S. Vulvodynia: an unrecognized diabetic neuropathic syndrome. Indian J Endocr Metab. 2013;17:787-9.

34. Livshits A, Seidman DS. Fertility issues in women with diabetes. Womens Health (Lond). 2009:5:701-7.

35. Meston CM, Derogatis LR. Validated instruments for assessing female sexual function. I Sex Marital Ther. 2002:28 Suppl 1:155-64.

36. Bargiota A, Dimitropoulos K, Tzortzis V, Koukoulis GN Sexual dysfunction in diabetic women. Hormones (Athens). 2011;10:196-206.

37. Ogbera AO, Chinenye S, Akinlade A, et al. Frequency and correlates of sexual dysfunction in women with diabetes mellitus. J Sex Med. 2009;6:3401-6.
38. Mills L. Sexual and reproductive health in women with diabetes Journal of Diabetes Nursing. 2015;19:272-5.

39. Tamás V, Kempler P. Sexual dysfunction in diabetes. Handb Clin Neurol. 2014;126:223-32.

40. Wing RR, Bond DS, Gendrano IN, et al. Effect of intensive lifestyle intervention on sexual dysfunction in women with type 2 diabetes: results from an ancillary Look AHEAD Study. Diabetes Care. 2013;36:2937-44.

41. Bourre JM. Dietary omega-3 fatty acids for women. Biomed Pharmacother. 2007;61:105-12.

42. Min Y, Djahanbakhch O, Hutchinson J, et al. Effect of docosahexaenoic acid-enriched fish oil supplementation in pregnant women with type 2 diabetes on membrane fatty acids and fetal body composition--double-blinded randomized placebocontrolled trial. Diabet Med. 2014:31:1331-40.

43. Panjari M, Davis SR. DHEA therapy for women: effect on sexual function and wellbeing. Hum Reprod Update. 2007;13:239-48.

44. Basson R. The complexities of female sexual arousal disorder: potential role of pharmacotherapy. World J Urol. 2002;20:119-26.

45. Basson R. Pharmacotherapy for women's sexual dysfunction. Expert Opin Pharmacother. 2009;10:1631-48.

46. Sarrel PM. Effects of hormone replacement therapy on sexual psychophysiology and behavior in postmenopause. J Womens Health Gend Based Med. 2000;9 Suppl1:S25-32.

47. Nijland EA, Weijmar Schultz WC, Nathorst-Boös J, et al. Tibolone and transdermal E2/NETA for the treatment of female sexual dysfunction in naturally menopausal women: results of a randomized active-controlled trial. J Sex Med. 2008;5:646-56.

48. Frank JE, Mistretta P, Will J. Diagnosis and treatment of female sexual dysfunction. Am Fam Physician. 2008;77:635-42. 